\title{
A Long Pulse Modulator for Reduced Size and Cost
}

\author{
H. Pfeffer, L. Bartelson, K. Bourkland et. al \\ Fermi National Accelerator Laboratory \\ P.O. Box 500, Batavia, Illinois 60510
}

July 1994

Presented at 21st International Power Modulator Symposium, Costa Mesa, CA, June 27 - 30, 1994 


\section{Disclaimer}

This report was prepared as an account of work sponsored by an agency of the United States Government. Neither the United States Government nor any agency thereof, nor any of their employees, makes any warranty, express or implied, or assumes any legal liability or responsibility for the accuracy, completeness, or usefulness of any information, apparatus, product, or process disclosed, or represents that its use would not infringe privately owned rights. Reference herein to any specific commercial product, process, or service by trade name, trademark, manufacturer, or otherwise, does not necessarily constitute or imply its endorsement, recommendation, or favoring by the United States Government or any agency thereof. The views and opinions of authors expressed herein do not necessarily state or reflect those of the United States Government or any agency thereof. 
A Long Pulse Modulator for Reduced Size and Cost

H. Pfeffer, L. Bartelson, K. Bourkland, C. Jensen, Q. Kerns, P. Prieto, G. Saewert, D. Wolff Fermi National Accelerator Laboratory

P.O. Box 500

Batavia IL 60510

Abstract

A novel modulator has been designed, built and tested for the TESLA test facility. This $e^{+} e^{-}$accelerator concept uses superconducting RF cavities and requires $2 \mathrm{~ms}$ of RF power at 10 pps. As the final accelerator will require several hundred modulators, a cost effective, space saving and high efficiency design is desired. This modulator uses a modest size switched capacitor bank that droops approximately $20 \%$ during the pulse. This large droop is compensited for by the use of a resonant LC circuit. The capacitor bank is connected to the high side of a pulse transformer primary using a series GTO switch. The resonant circuit is connected to the low side of the pulse transformer primary. The output pulse is flat to within $1 \%$ for $1.9 \mathrm{~ms}$ during a $2.3 \mathrm{~ms}$ base pulse width. Measured efficiency, from breaker to klystron and including energy lost in the rise time, is approximately $85 \%$.

\section{Introduction}

This paper is a description of the TESLA $5 \mathrm{MW}$ modulator built at Fermilab and presently in use as a test stand at DESY. We examined several different modulator techniques and chose a new design suited to a long ( $2 \mathrm{~ms}$ ) output pulse. The requirements for the modulator are:

\begin{tabular}{|c|c|c|c|c|}
\hline $\begin{array}{c}\text { Pulse Widih } \\
(99 \% \text { to } 99 \%)\end{array}$ & $\begin{array}{c}\text { Output } \\
\text { Voltage }\end{array}$ & $\begin{array}{c}\text { Output } \\
\text { Current }\end{array}$ & $\begin{array}{c}\text { Repetition } \\
\text { Rate }\end{array}$ & $\begin{array}{c}\text { Operating } \\
\text { Lifetime }\end{array}$ \\
\hline $2 \mathrm{~ms}$ & $130 \mathrm{kV}$ & $95 \mathrm{~A}$ & $10 \mathrm{pps}$ & $>10$ years \\
\hline
\end{tabular}

\section{Design Approach}

Our initial approach to the modulator design was a line type PFN with a step-up transformer. Although we realized the $2 \mathrm{~ms}$ pulse length was rather long for this technique, a 24 section, $8.3 \Omega$ PFN was designed to meet the specifications. Iron core inductors were used because of the long pulse length and the need to reduce physical sizc. The PFN that we designed was $2 \mathrm{~m} \times 4 \mathrm{~m} \times 2 \mathrm{~m}$ high and had a component cost of approximately $225 \mathrm{k} \$$. The total modulator component cost estimate was $535 \mathrm{k} \$$.
A modulating anode supply was then investigated. The estimated cost of this system is less than the PFN approach. However, no switch tube was available that would meet performance requirements. Additionally, the efficiency of the modulated anode approach is significantly lower than the PFN approach.

We next looked into a switched-capacitor design. Our main concern about this approach was the large amount of stored energy ( $1 \mathrm{MJ}$ ) that would be required. Then one of us, Q. Kerns, suggested an ingenious way to reduce stored energy and cost.

The classic text by Lebacgz and Glasoe shows how the output of hard tube modulator may be flattened by the use of a parallel $L R$ circuit in series with the load [1]. This circuit has power loss; however the reduction in stored energy is impressive. Kerns' idea reduces the stored energy by adding low loss passive components to the modulator. A switched capacitor bank is used. However, it is allowed to discharge approximately $20 \%$ during the pulse. This large droop is then compensated for by the use of a low impedance resonant LC (" bouncer ") circuit. This greatly reduces the loss over the L R circuit but retains the benefit of lower stored energy. The estimated cost of this bouncer circuit was $20 \mathrm{k} \$$, and its size was approximately $2 \mathrm{~m}$ by $1 \mathrm{~m}$ by $2 \mathrm{~m}$. The component cost estimate for this modulator was under $400 \mathrm{k} \$$, and we decided to pursue this design.

\section{Principles of Operation}

The modulator topology is shown in Figure 1. The main capacitor bank, $\mathrm{Cl}$, is charged to approximately $10 \%$ higher than the required output voltage, while the bouncer, L3 \& $\mathrm{C} 2$, is charged to $10 \%$ of the required output voltage. To produce an output pulse, the bouncer resonant circuit switch, $\mathbf{S 4}$, is closed, and the capacitor starts to ring with the inductor. At the appropriate time, the GTO switch, S1, connecting the main capacitor bank to the pulse transformer is closed. After the $2 \mathrm{~ms}$ output pulse length, the GTO switch is opened. The bouncer circuit then continues to ring through its full cycle. Figure 2 shows the bouncer voltage and main capacitor bank voltage. The bouncer waveform is subtracted from the main capacitor bank waveform, and Figure 3 shows the resultant output voltage in full size and expanded versions. The specifications are clearly met.

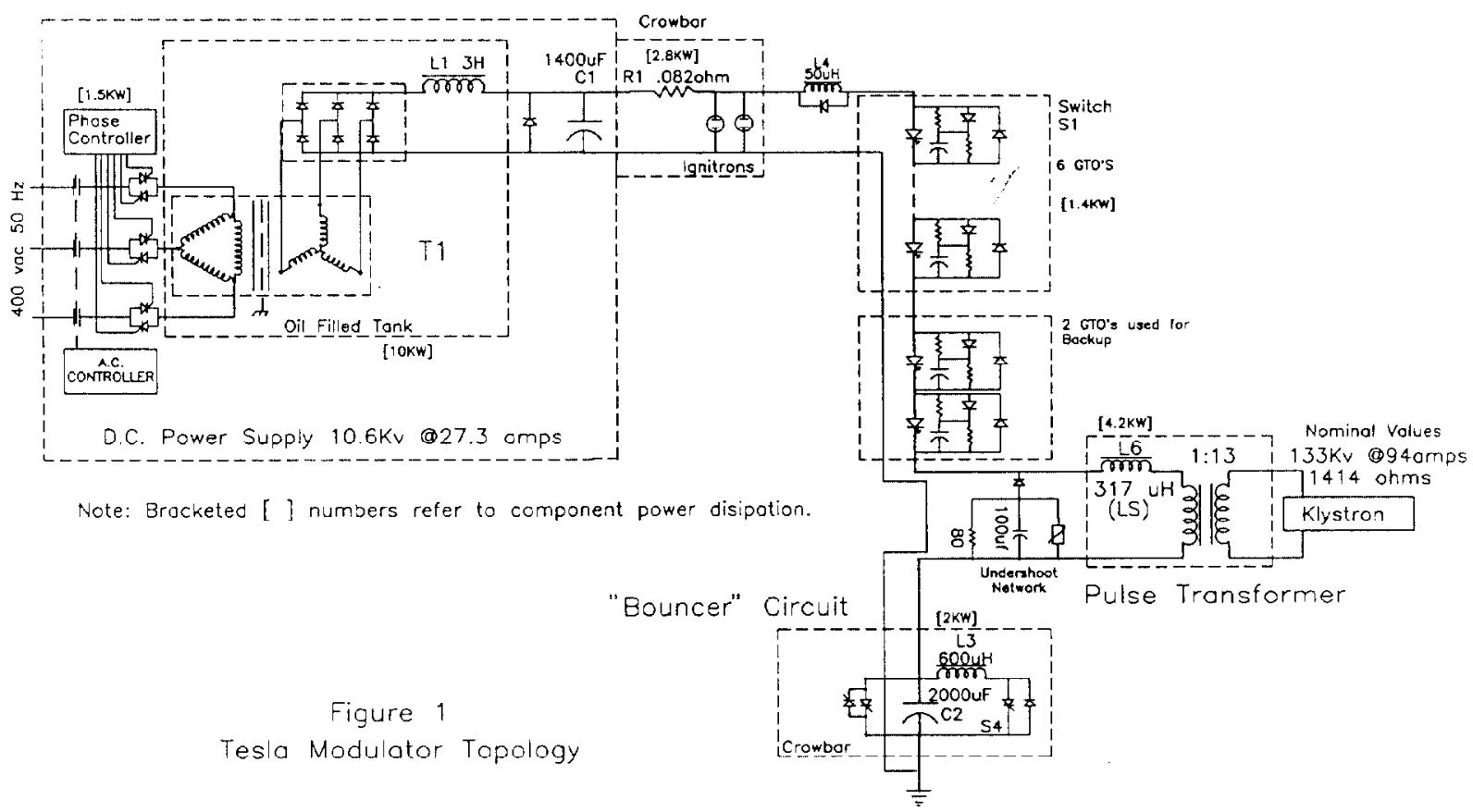

Work stpported by the U. S. Depaltment of Energy under contract No. DE-ACO2-76CHO3000 


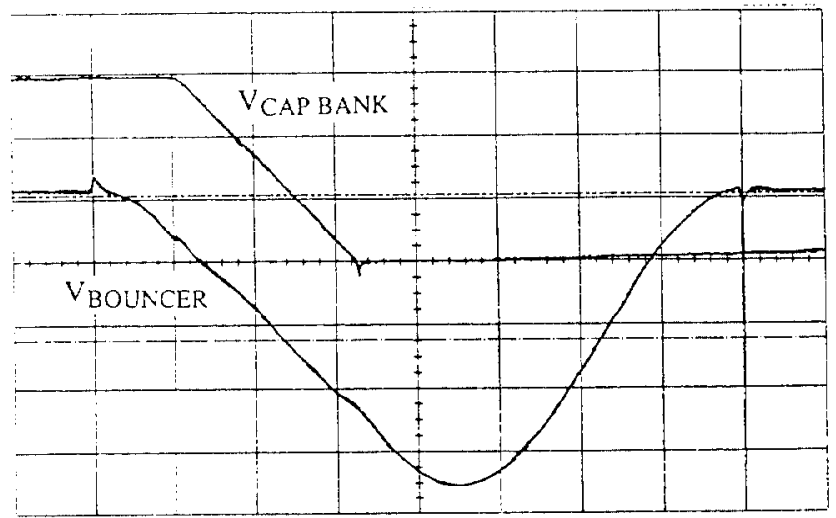

Figure 2, Main Capacitor Bank Voltage ( Top ) and Bouncer Voltage ( 500 V/div, 1 ms/div, Main Capacitor Bank Zero Suppressed)

\section{Key Modulator Components}

Several components are unique to this modulator. A reliable and robust closing and opening switch is required, so a series stack of six GIOs (Gate lum Off thyristor) is used. The bouncer circuit must be designed with low loss and the maximum impedance consistent with effective output regulation. The main capacitor bank must be designed for crowbar operation and capacitor fault conditions. The bus bar must have low inductance between all major components and must be designed to tolerate the crowbar current between the main capacitor bank and the crowbar switch. The pulse transformer must have a very large volt second rating and a relatively low leakage inductance. Mechanical vibration from the system must be kept to a minimum because the RF superconducting cavities are nearby.

\section{GTO Switch}

The switch element in the transformer primary circuit must be rated to operate at $12 \mathrm{kV}$ and switch $1200 \mathrm{Amps}$ both on and off. We seriously considered the use of a series SCR switch with a forced comimutation circuit to turn it off. The design effort revealed that the forced commutation circuitry was costly, dissipative and complex. A series GTO switch seemed like a natural choice for this application. We were hesitant to proceed due to the scarcity of documented series GTO applications. We decided to use the GTOs after studying their manuals and talking to the designer of a successful commercial application [2]

The switch is a series string of six devices as shown in Figure 4. Two more series GTOs are controlled independently and constitute a backup switch that operates in conjunction with the capacitor bank crowbar if the main switch fails to open properly. The GTOs we have used are GEC type DG758BX45. The key GTO ratings are listed below.

$\begin{array}{lll}\mathrm{I}_{\mathrm{igqm}} & 3.0 \mathrm{kA} & \text { Maximum controllable current } \\ \mathrm{V}_{\mathrm{d} r m} & 4.5 \mathrm{kV} & \text { Maximum repetitive off state voltage } \\ \mathrm{T}_{\mathrm{g} . \mathrm{S}} & 25.0 \mu \mathrm{s} & \text { Maximum tum off storage time }\end{array}$

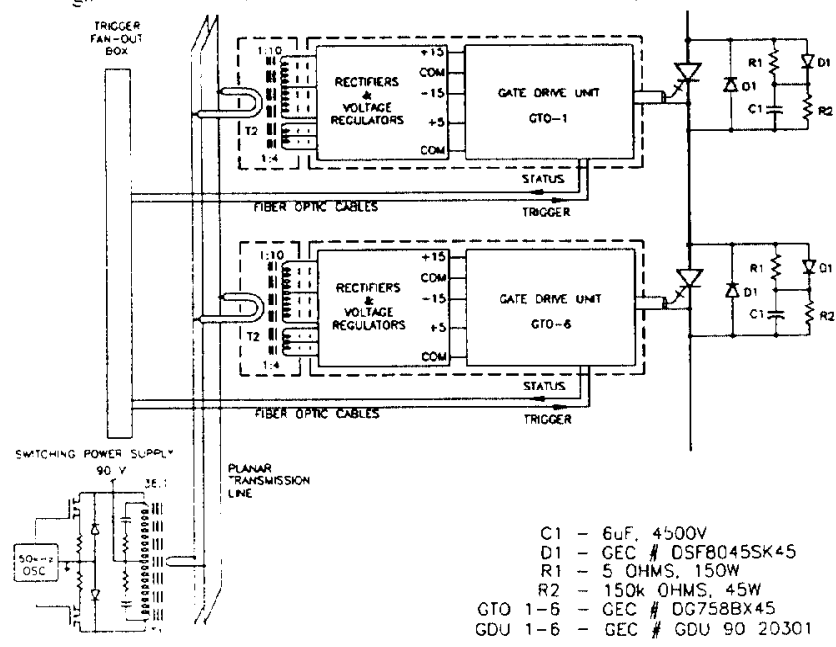

Figure 4, GTO Switch Schematic

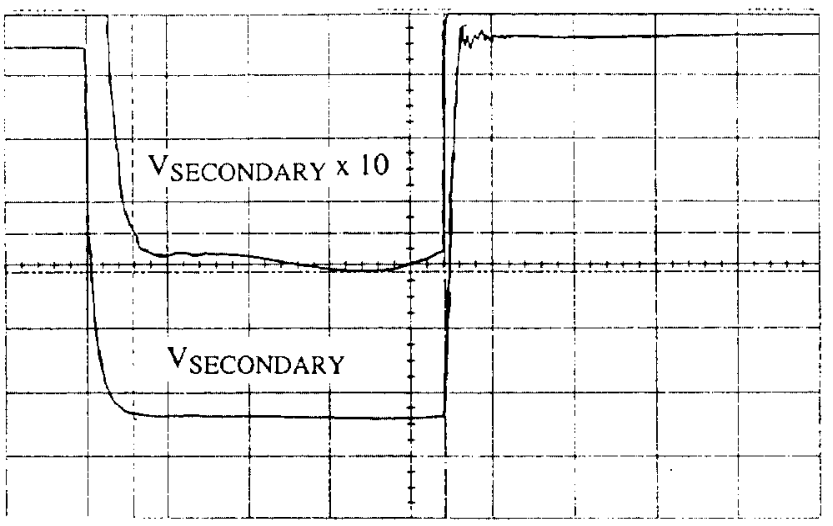

Figure 3, Expanded Secondary Voltage (Top) and Secondary Voltage

( $2 \mathrm{kV} / \mathrm{div}, 20 \mathrm{kV} / \mathrm{div}, 0.5 \mathrm{~ms} / \mathrm{div}$, Expanded Zero Suppressed)

The snubber circuits are those recommended by the vendor. The gatc drive units are purchased from GEC/Plessey. They are controlled by fiber optic cables, but require isolated power.

We designed a high current, low voltage $50 \mathrm{kHz}$ switcher supply capable of delivering $10 \mathrm{~W}$ of isolated power to each of the eight gate drive units. Power from the switcher supply is distributed using a planar transmission line connected to the secondary terminals of a ferrite (MN100) step-down transformer ( T1, Figure 4). Eight one turn loops of the center conductor of RG-17 cable are connected in parallel across the planar transmission line. These are the primary windings of step-up transformers ( T2 ) located at each gate drive unit. The RG-17 cable provides the voltage isolation between the switcher supply and the GTO gate-drive units. At the step-up transformers, power is converted to $\pm 15 \mathrm{~V}$ and $+5 \mathrm{~V}$ and used by the gate drive units. The step-up transformers are driven in parallel rather than in series. The series configuration suffers from unequal drive voltage sharing due to variations in loading of the individual gate drive units. The unequal sharing is exacerbated by the use of voltage regulators in the secondary circuits.

Although the nominal primary current is $1200 \mathrm{~A}$, a klystron gun spark causes the current to rise to $1800 \mathrm{~A}$. The extra current is generated because of the $20 \mu \mathrm{s}$ storage time $\left(\mathrm{T}_{\mathrm{gs}}\right)$ of high current GTOs. When a gun spark is detected, the switch is immediately gated off. During the storage time the switch current rises at a rate of $27 \mathrm{~A} / \mu \mathrm{s}$, as limited by the pulse transformer leakage inductance $(320 \mu \mathrm{H})$ and the inductance of a $50 \mu \mathrm{H}$ coil in the primary circuit. We chose $3 \mathrm{kA}$ GTOs in order to have sufficient margin to be able to reliably tum off at $1800 \mathrm{~A}$. Figure 5 shows the primary current rising to $1800 \mathrm{~A}$ before turning off in an actual gun spark.

The switch turn-off transients have been controlled in two ways. First, the turn-off voltage sharing has been balanced through the matching of device storage times to within $2.5 \mu \mathrm{s}$. Second, the turn-off voltage overshoot has been limited by the use of planar transmission line buswork to limit stray primary circuit inductance to less than $2 \mu \mathrm{H}$. In addition, the snubber network inductance has been limited to $140 \mathrm{nH}$.

In order to protect the switch from catastrophic failure, we added control circuits to monitor and react to such situations as lack of cooling water flow, excess heat sink temperature, malfunctioning gate drive units, or the failure of a single GTO.

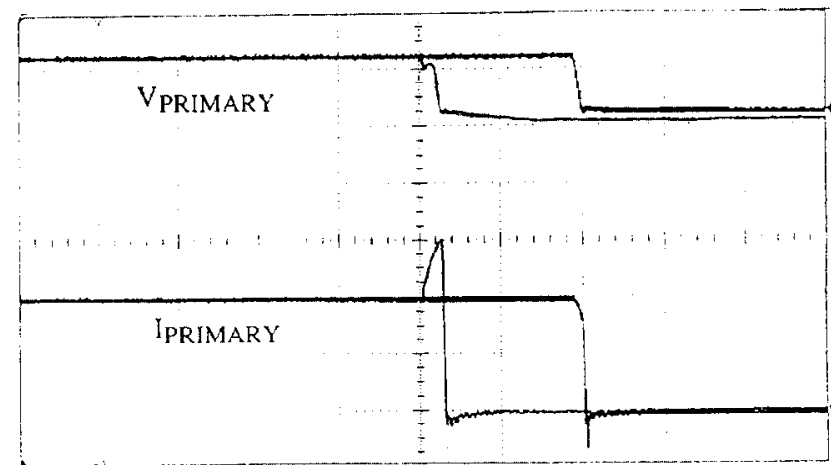

Figure 5. Primary Voltage (Top) and Current During a Gun Spark ( $10 \mathrm{kV} / \mathrm{div}, 600 \mathrm{~A} / \mathrm{div}, 100 \mu \mathrm{s} / \mathrm{div}$ ) 
The bouncer circuit is a resonant LC circuit that is placed in series with the pulse transformer primary. The bouncer is triggered to ring through its single cycle sine wave just before the main pulse is started. As shown in Figure 6, the bouncer is in the linear part of its waveform as the output pulse goes through the bouncer circuit. The linear voltage is subtracted from the main capacitor bank voltage, and compensates for the capacitor bank $20 \%$ droop. The resultant output pulse is flat to within $1 \%$.

Two ideas have been key for us in understanding the operation of the bouncer. The first concerns the bouncer impedance. If the bouncer were designed at an infinitesimally low impedance level, the presence of the pulse current going through it would make a negligible distortion of its sine wave, and the subtraction of the capacitor droop would be straightforward. Unfortunately, such a circuit would be infinitely large and expensive. On the other hand, the sine wave of a high inpedance version would be drastically distorted if the pulse curtent were much larger than the bouncer resonant current. We started with a design in which the peak bouncer current was twice the pulse current. Our SPICE model showed that although the bouncer waveform was somewhat flattened during the current pulse, the droop compensation still worked at the $1 \%$ level once the bouncer starting voltage was raised to adjust for the flattening effect. If we doubled the impedance of the bouncer components, the model no longer worked at the $1 \%$ level. We therefore used our initial impedance choice.

The second key idea concerns the power flow into the bouncer circuit. Figure 6 shows that the bouncer capacitor voltage has equal positive and negative parts during the current pulse. During the first half of the pulse, the pulse current adds energy to the capacitor, and during the second half of the pulse it subtracts an equal amount. The only losses in the bouncer circuit are due to the dissipation factors of the bouncer components. The components were specificd to dissipatc less than $2 \mathrm{~kW}$ at full power operation.

It is interesting to note that if the pulse is shifted earlier in the bouncer waveform, a nel positive energy is deposited in the bouncer capacitor. We make use of this feature by adjusting the relative timing of the bouncer and output pulse so that the bouncer is charged to the desired level. No bouncer capacitor charging supply is required! A closer look at Figure 6 reveals that the bouncer voltage zero crossing is slightly later than the midpoint of the current pulse since we were using this feature at that time.

We were surprised to find how stable this charging system turned out to be. For any timing relationship the bouncer voltage is stable. If the pulse timing is set too late, the bouncer capacitor charges to a lower stable operating voltage, and the output pulse has a negative slope. If the pulse timing is set too early, the bouncer capacitor charges to a higher stable operating voltage, and the output pulse has a positive stope. It is stable because as the bouncer charges to a higher voltage, the uutput pulse voltage and current are reduced. The linear portion of the sine wave therefore has a larger slope (less flattening), and the average bouncer capacitor voltage during the pulse is made more negative. The net power delivered to the bouncer capacitor is thus decreased until a stable balance point is reached.

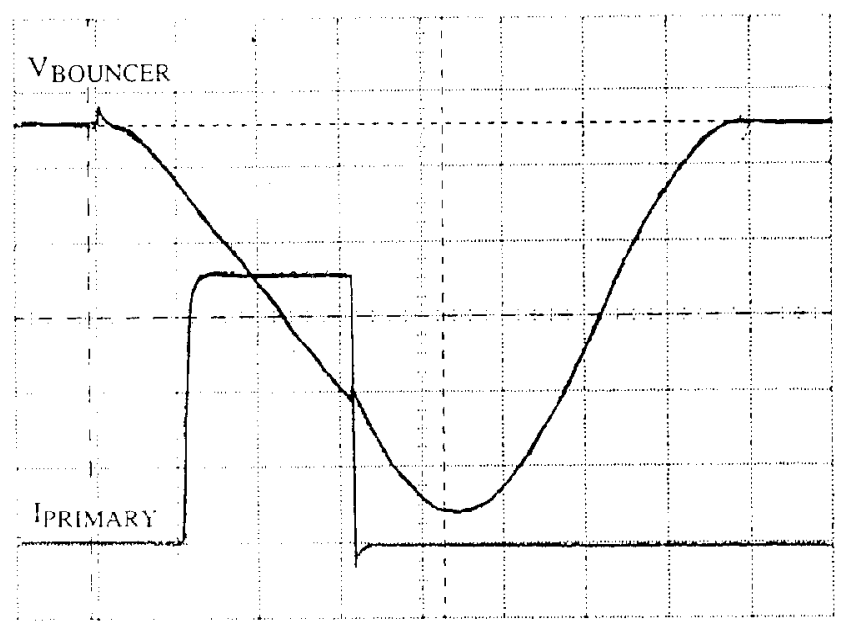

Figure 6. Bouncer Voltage (Top) and Modulator Primary Current (500 V/div, $300 \mathrm{~A} / \mathrm{div}, 1 \mathrm{~ms} / \mathrm{div}$ )
The main capacitor bank has the standard concerns of a large stored energy application, and the additional concerns related to its high-speed crowbar. The crowbar circuit must remove the GTO switch input voltage within microseconds in order to protect the klystron from a switch failure. The crowbar resistive dump is in the main circuit path of the GTO switch. This enables the crowbar to remove the GTO switch input voltage in $4 \mu$ s while the capacitor bank is undergoing a $100 \mu$ s discharge. However, the resistance must be minimized to avoid excessive dissipation during normal operation. This minimal resistance causes large crowbar currents but has been chosen to critically damp the crowbar circuit.

The capacitor bank was divided into eight sections of $175 \mu \mathrm{F}$ at $10 \mathrm{~kJ}$ each. Each section is connected to the main bus with a $0.1 \Omega$ resistor to absorb the energy during a capacitor fault. Since a crowbar is a recoverable event and crowbar current and capacitor fault current are comparable, commercially available fuses could not be used.

The crowbar of the main capacitor bank is a back-up protection measure for the klystron, so we have made it redundant. The crowbar consists of two independent NL8900 Hg ignitron switches, each capable of the full discharge current $(70 \mathrm{kA})$. Each ignitron is fired by an independent trigger circuit from independent fault detection logic.

The buswork between the main capacitor bank and the crowbar was designed as planar transmission line to minimize the inductance in the GTO circuit. This bus must also handle the forces during a crowbar, and be corona free at the $12 \mathrm{kV}$ operating level. Lexan ${ }^{\circledR}$ ( polycarbonate) was selected, because of its mechanical and electrical properties, both to insulate the bus conductors and to clamp them together. Extensive $A C$ and DC hipotting of the buswork was done to insure a low partial discharge. Lexan's ${ }^{\circledR}$ corona threshold lcvel was higher than either glass reinforced epoxy or fiber reinforced paper.

\section{Pulse Transfomer}

The pulse transformer was also a challenging component The primary leakage inductance was required to be less than $500 \mu \mathrm{H}$, and the primary magnetization was to be less than 12 A with at least $25 \mathrm{~V} \cdot \mathrm{s}$ before saturation. The transformer as delivered is large, approximately $1 \mathrm{~m}$ by $2 \mathrm{~m}$ by $1 \mathrm{~m}$, with $320 \mu \mathrm{H}$ of leakage inductance and $7 \mathrm{~A}$ magnetizing current at $27 \mathrm{~V} \cdot \mathrm{s}$. The output voltage divider met specifications, however it had to be rebuilt to avoid excessive pickup during gun spark transients. There is very little acoustic noise from the transformer; the stiff core clamps and vibration isolation mounting of the core worked very effectively.

\section{Klystron Protection}

Klystron and modulator availability is a critical element of reliable linac operation. Protection of the klystron during gun sparks is an important element of the modulator design. The use of a pulse transformer makes possible an all solid state, and therefore more reliable and lower maintenance, modulator. However this same pulse transformer complicates the problem of protecting the klystron during a gun spark.

The klystron manufacturer has put a limit of $20 \mathrm{~J}$ on the amount of energy deposited into the klystron during a gun spark. During a normal pulse, $270 \mathrm{~J}$ is stored in the transformer leakage inductance. This energy must be removed from the transformer before it can be deposited into the sparking klystron. Crowbatring the primary circuit is not sufficient to remove this energy; the GTO switch must be opened so that the primary voltage can be inverted to at least 400 volts to rapidly reduce the leakage current.

The voltage inversion is controlled by an undershoot network installed across the transformer primary. The network is a parallel combination of a resistor, a capacitor, and a ZOV transient suppressor. The resistor absorbs the transformer magnetizing current and resets the core during normal operation. The capacitor absorbs the leakage inductance current during normal pulse turn-off, and limits the undershont to $700 \mathrm{~V}$. The $70 \mathrm{~V}$ clamps the undershoot to $1600 \mathrm{~V}$ following a gun spark. The capacitor would otherwise overcharge since the klystron does not share in absorbing the leakage inductance energy following a gun spark.

For the undershoot network to work at all, the GTO switch must first be opened. There is an alternate mechanism for opening the primary circuit if the GTO switch fails. If the primary current reaches 
a threshold indicating that the GTO has not turned off, the backup system is used. The backup systen crowbars the main capacitor bank and opens a pait of single GTOs in series with the main switch. Redundant control systems are used to monitor the current and control the crowbar and GTO switches to insure reliability.

Figure 7 shows the secondary current and voltage during an actual gun spark. Gun spark energy for this event is less than $4 \mathrm{~J}$ The spark protection circuitry has functioned well through 40 gun sparks to date.

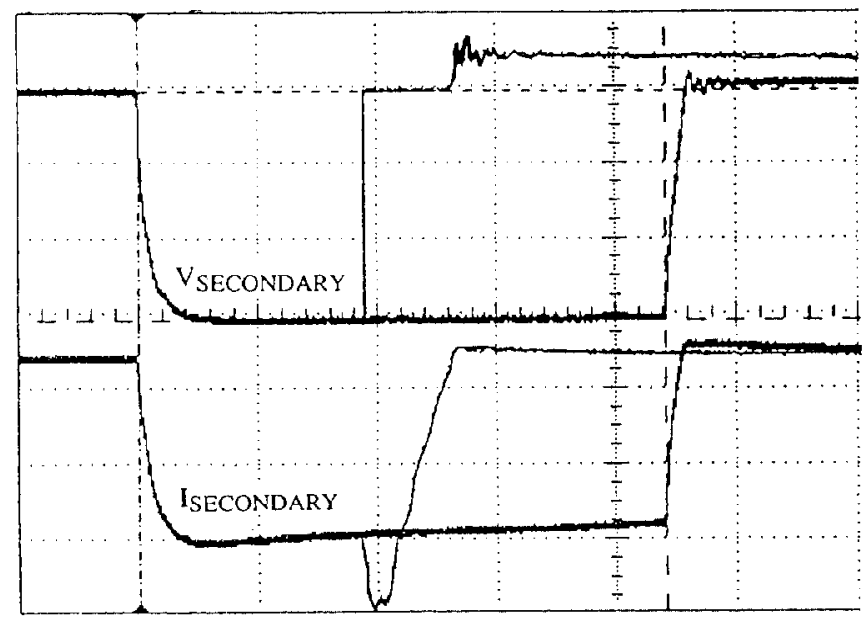

Figure 7, Secondary Voltage ( Top ) and Current During a Gun Spark ( $40 \mathrm{kV} / \mathrm{div}, 40 \mathrm{~A} / \mathrm{div}, 0.5 \mathrm{~ms} / \mathrm{div}$ )

\section{Modulator Controls}

The controls system used for this modulator is an in-house design rather than commercial equipment. Most of the electronics modules are copies or modifications of equipment designed for the recent Femi LiNAC upgrade. The controls consist of three functional black:

1. Signal transmission modules consisting of current drivers and receivers for transmission of analog signals from the high power section to the controls section, and fiber optic modules for the transmission of digital control signals to the high power section.

2. Analog circuit modules 10 generate the required signals for modulator operation and to compare the signals to references and generate er or signals.

3. Digital modules which latch error signals and perform system control and timing correlation of the modulator switches.

There are two independent systems that monitor gun sparks. The first system monitors secondary voltage and current and responds to the rapid collapse of the gun voltage. The second system monitors the primary current with two independent current transformers. This system detects both gun sparks and failure of the system to respond to gun sparks. If the normal protection malfunctions, it initiates the backup protection system. In addition, all control circuits related to gun sparks have parallel redundancy.

\section{Operational Results}

The primary result is that the modulator works well and meets specifications. Operation at required voltage, pulse width and duty cycle were achieved. In addition, the complete modulator and klystron system has been installed at DESY in Hamburg Germany after commissioning at Fermilab. Recommissioning at DESY took only five weeks from unpacking to full RF power. A number of interesting problems occurred during the initial commissioning phase at Formilat.

Various changes to the pulse transformer auxiliary circuits were made as a result of studies of spark related transients. These studics were done by using a triggered spark gap across a dummy foad on the transformer secondary. The capacitor divider circuit necded modification to handle secondary transients, and high frequerry by pass capacitors were alded to suppress voltage transients on the transiormer primary.

There was one GTO device fature during the commissioning phasc. This occured when the capacitor bank was crowbarred just as the GTO switch opened. The controls system also suffered a transient that caused crroncous status and the failure of a logic chip. We don't fully understand what happened, but we changed a crowbar theshold to prevent a recurrence and more carefully shiclded some of the status monitoring cables in the modulator cabiner. No similar failure has happened since.

We have experienced some problems with the pulse transformer. On three occasions the waveforms associated with gun sparks looked strange, indicative of a turn-to-turn transformer short initiating after the gun spark. Upon turning the modulator back on after these events we experienced low voltage turn-to-turn transformer shorts which cleared up after two pulses. Inspection of the transformer was inconclusive and we decided to run at $115 \mathrm{kV}$ rather than $122 \mathrm{kV}$ in order to minimize gun sparks. The subsequent three gun sparks that we experienced at this new level showed no signs of turn-to-turn shorting. Since the klystron generates surficient power for test stand operation at the $115 \mathrm{kV}$ level, our operational approach for now is to run at this level and investigate transformer replacements.

The ability to vary the pulse length easily has been very useful, especially in conditioning the klystron. The klystron came to Fermilab conditioned with a $500 \mu$ s pulse. We lengthened the pulse over several days completing the conditioning process.

\section{Power Efficiency}

The power efficiency of this modulator is an important criterion. We measured the efficiency while running at $122 \mathrm{kV}$ with a $2.2 \mathrm{~ms}$ pulse length and $10 \mathrm{pps}$. The $480 \mathrm{VAC}$ power was $274 \mathrm{~kW}$ as measured by a Yokagawa power meter. The usable pulse power as defined by the output voltage between $+1.0 \%$ and $-5 \%$ of the nominal, was $236 \mathrm{~kW}$, and the efficiency is $86 \%$. Our calculated efficiency is $89 \%$ and Figure 1 shows the calculated dissipation in vatrious modulator components. For future systems, tradeoffs between component cost and power efficiencies can be explored

\section{Costs}

The cost of the modulator components was approximately $370 \mathrm{k} \$$. This includes approximately $20 \mathrm{k} . \mathrm{s}$ for the bouncer circuit, $25 \mathrm{k} \$$ for the controls, $50 \mathrm{k} \$$ for the GTO swith. $75 \mathrm{k} \$$ for the $400 \mathrm{VAC}$ phase controller and power transformer, and $90 \mathrm{k} \$$ for the pulse transformer. Fermilab labor costs are not included.

\section{$\underline{\text { References }}$}

[1] Glasoe, G. N., Lebacqz, J. V., Pulse Generators, pp. $165-172$, McGraw Hill, 1948, First Edition

[2] Espelage, Paul M., Symmetrical GTO Current Source Inverter..., IAS 1988, Vol. 1 pp. $302-306,1988$ IEEE Industry Applications Annual Meeting. 